\title{
Eski Uygurca sarıt (kıl-) ifadesi üzerine
}

\section{Hasan İ́ं்}

\begin{abstract}
APA: İsi, H. (2019). Eski Uygurca sarıt (kll-) ifadesi üzerine. RumeliDE Dil ve Edebiyat
\end{abstract} Araşttrmaları Dergisi, (17), 40-46. DOI: 10.29000/rumelide.656605.

\section{Öz}

Eski Uygurca, Budizm ve Manihaizm temelli dinî eserlerden meydana gelmiş söz varlığının ağırlıkta olduğu felsefî bir dönemdir. Budizm ve Manihaizm gibi dinlere ait felsefî görüşlerin anlatıldığı bu dönem, sahip olduğu dinî eserlerle ilgili öğretiler içerisinde yer alan uygulamaları halka aşılayan sisteme sahiptir. Eski Uygur Türkçesinin sahip olduğu bu felsefî yön, Türk dilinin işlenmişliğini göstermesi bakımından önemlidir. Özellikle çok dilli Uygur rahiplerinin Budizm temelinde tercüme faaliyetleri neticesinde ortaya koydukları bu dinî terminoloji, hem yabancı kelimelerden hem de Türkçe kelimelerden oluşan birikimin ve işlenmişliğin ürünüdür. Kültürel etkileşimler neticesinde gelişen dinî yaşam doğrultusunda halka anladığı dille seslenmeyi isteyen Uygur rahipleri, bu doğrultuda Budizm ve Manihaizm gibi dinlere ait sözcükleri, öncelikle Türkçeleştirme yoluna girerek Türk dilinin terim türetme gücünü ortaya koydukları kelimelerle sergilemişlerdir. Çok dilli Uygur rahipleri, yabancı sözcüklere Türkçe karşılıklar verme konusunda Türk dilinden istifade edemedikleri durumda, kaynak dil konumundaki Sanskritçe sözcükleri Toharca, Çince ve Soğdca gibi dillerden alarak Türkçe ve yabancı sözcüklerden oluşan dinî bir terminoloji ortaya koymuşlardır. Türk dilinin dinî terminolojisiyle ilişkili terimlerden biri de, ilk kez Eski Uygurcaya ait metinlerde karşımıza çıkan "akılda tutmak, belli bir ritimle bir ritüeli tekrar edip ezberlemek" anlamlı sartt (kll-) ifadesidir. Bu ifade, özellikle, Uygurların Yüan hanedanlı̆̆ı döneminde Tibet Budizmine dayalı Tantrik Türk Budizmi içerisinde kilit roldeki "büyü formülleri”ni gösteren mantra ve dhāraṇ̄ kavramlarının uygulanma yöntemiyle ilgili Budist bir terimdir. Bu çalışma ile, öncelikle sarıt (kıl-) ifadesinin geçtiği metinlere yer verilerek ifadenin sahip olduğu kullanım sıklığına ve Uygur imlasındaki gösteriminde yaşanan ikiliğe yer verilecektir. İfadenin tanıklandığı metinlerin ait olduğu Budist gelenek yazılı tanıklardan belirlenerek sarıt ( $k \imath l-)$ deyimini oluşturan sartt sözcüğü üzerine köken bilgisel değerlendirmelere girişilecektir. İlgili tanıkların yer aldığı metinlerde, araştırmacıların köken noktasında değerlendirmelerden kaçışı, sözcüğün belirsizliğe sahip oluşundan kaynaklanmaktadır. Bu çalışma ile, sınırlı sayıda metinde yer alan sarıt ifadesinin kökeni noktasında ortaya konulan Türkçe ve İranî diller görüşü, ilgili bölüm içerisinde tartışılarak sözcüğün sahip olduğu oluşuma değinilmeye çalışılacaktır. Bu bölümde, sözcüğün Türkçe oluşu noktasında var olan *sari+t biçiminin kök ve ek arasında uyumsuzluk oluşturması, ifadenin Uygurların etkileşim içerisinde olduğu bir dilden alındığı görüşünü doğurmaktadır. Özellikle Eski Uygurca içerisinde mantra, dhāraṇī ve sūtra gibi büyü formüllerinin mırıldanarak tekrar edilmesi ritüeliyle uyuşan Soğdca srūtya ve Pehlevice $s r o ̄ d$ kelimeleri, sözcüğün geldiği kaynak dille ilişkili ifadelerdir. Eski Uygurca içerisinde İranî dillerle temasın özellikle Soğdca ve Toharca ile gerçekleştiği göz önüne alındığında, ifadenin kökeni noktasında kaynak dilin Soğdca ve Toharcaya yöneldiği görülmektedir. Bu doğrultuda, sarıt sözcügünün kökeni noktasında tartışılan ve üzerinde görüş bildirilen nokta, kelimenin Toharcada yer almayışı ile ifadenin Soğdcadan Eski Uygurcaya srūtya biçiminden aktarıldığı üzerinedir.

Anahtar kelimeler: Eski Uygurca, dinî terminoloji, mantra, dhāraṇī ve sūtra. 


\title{
On the expression of Old Uyghur sart (kıl-)
}

\begin{abstract}
Old Uyghur Turkic, Buddhism and Manichaism-based religious works is a philosophical period of vocabulary predominantly. This period in which the philosophical views of religions such as Buddhism and Manichaism are explained, has a system that instills the practices in the doctrines about religious works. This philosophical aspect of Old Uyghur Turkic is important in terms of showing the processing of Turkic language. This religious terminology, which is revealed by multilingual Uighur priests as a result of Buddhism translation activities, is the product of the accumulation and processing of both foreign words and Turkish words. The Uyghur priests, who wanted to speak to the public in line with the religious life developed as a result of cultural interactions, displayed the words belonging to religions such as Buddhism and Manichaism with the words they put forward in the way of Turkishization by firstly introducing the power of Turkic language to derive terms. The multilingual Uyghur priests, when they could not benefit from the Turkic language in terms of providing Turkic equivalents to foreign words, obtained a religious terminology consisting of Turkic and foreign words by taking the Sanskrit words as the source language from languages such as Toharian, Chinese and Sogdian. One of the terms related to the religious terminology of the Turkic language is "keeping in mind, repeating and memorizing a ritual with a certain rhythm". This is a Buddhist term, in particular, about the way in which the Uyghurs mantra and dhärañ are applied to the key role of "magic formulas" in Tantric Turk Buddhism based on Tibetan Buddhism during the Yuan dynasty. In this study, first of all, the texts in which the expression sarıt (kıl-) is mentioned will be used and the frequency of usage of the expression and the duality experienced in the expression of Uyghur will be included. The Buddhist tradition to which the texts are witnessed will be determined from the written witnesses and the information about the origin of the word sart, which forms the phrase sart (kul-), will be attempted. In the texts of the relevant witnesses, the researchers' escape from evaluations at the point of origin stems from the uncertainty of the word. In this study, the opinion of Turkic and Iranian languages put forward at the point of origin of sart expression in a limited number of texts will be discussed in the relevant section and the formation of the word will be discussed. In this section, the discrepancy between the root and the suffix of *sari $+t$, which exists at the point where the word is Turkic, leads to the opinion that the expression is taken from a language in which Uyghurs interact. Especially in Old Uyghur, the words Sogdian srūtya and Pahlavi srōd, which are consistent with the ritual of mumbling repetition of magic formulas such as mantra, dhārañi and sūtra, are expressions related to the source language of the word. Considering that the contact with Iranian languages in Old Uyghur especially took place with Sogdian and Toharian language, it is seen that the source language is oriented towards Sogdian and Toharian language at the point of origin. In this respect, the point discussed and discussed on the point of origin of the word sart is that the word is not included in Toharian and that the expression is transferred from Sogdian to Old Uyghur in srūtya form.
\end{abstract}

Keywords: Old Uyghur, religious terminology, mantra, dhāraṇī and sūtra.

\section{Giriş}

Türk dilinin felsefî ve soyut yönünü sahip olduğu gelişkin üslupla yansitan Eski Uygurca, Uygur Türklerinin kültürel ve dinî amaçlar çerçevesinde, etkileşime girdikleri halklarla oluşturdukları temaslar etkisinde kapsamlı eserlerin ortaya konduğu edebi bir dönemdir. Zamanla Uygur toplumu içerisinde 
kök salan Budizm doğrultusunda gelişen Türk dili, bu dine ait dinî terimleri Budizmin kaynak dilleri olan Sanskritçe ve Çince yerine doğrudan etkileşime girdikleri Soğdlar ve Toharlardan almıştır. Türkçenin dinî terminolojisinin ilk ürünlerinin verildiği dönem olma özelliği de taşıyan Eski Uygurca, Budizmin kaynak dillerinden olan Sanskritçe ve Çince dinî terimleri, bir yandan Soğdca ve Toharcadan kopyalarken diğer yandan Uygur rahiplerinin kurmuş oldukları tercüme heyetiyle ilgili dinî terimlere Türkçe karşıllklar verme yolunu izlemiş̧ir. Felsefî üsluba sahip olan Budizmi anlatma adına, halkın anladığı dille basit bir anlatım tarzını amaç edinen Uygur rahipleri, ilgili terimi basitleştirme ve yaygınlaştırma adına eş anlamlı Türkçe sözcükle bu yabancı terimi bir arada kullanıp yabancı sözcüğün halk arasında yaygınlaşmasını istemişlerdir.

Bu çalışma, ilk kez Eski Uygurca metinlerde tanıklanan özellikle Budizm temelli Tantracı geleneğin ürünü olan dhāraṇ̄ "sihir" anlatılarının akılda tutulmasını, ezberlenmesini karşlayan sarıt (kl-) ifadesinin dönem metinleri içerisindeki kullanımlarını ve kökenini belirlemeyi hedeflemektedir. Tibet Budizmi olarak bilinen ve Uygurlar tarafından Türk Budizmi ile sentezlenen Tantrik Türk Budizminin mantra ve dhâraṇi türlerinin zihinlere yerleşmesinde etkin olan sarıt sözcüğü üzerine yapılan sinırlı sayıdaki değerlendirmeleri çözüme ulaştırmak isteyen bu çalışma, sınırlı sayıdaki yazılı tanığa rağmen sözcügün kökeni noktasında kesin görüşlere ulaşmayı hedeflemektedir.

\section{Eski Uygurca metinlerde sart (kal-) ifadesi}

Çalışmanın bu bölümünde, ilk kez Eski Uygurca metinlerde tanıkladığımız sarıt (kıl-) kelimesinin dönem metinlerinde sahip olduğu kullanımlara yer verilerek ilgili sözcüğün Budizm içerisinde ifade ettiği kavramsal değer ortaya konmak istemiştir.

AY I 646-649: ol xung uțik tägsinü drni-lïץ munčuq tägsinü turur saqünïp drni-sïn tnginčä yaraү-ïnča birgär sarït qülu sözlägü ol (Zieme 1996: 114), (AY 1994: 71). "da $\beta$ die Silbe hūm, sich dreht, da $\beta$ das Dhāraṇī-Juwel sich dreht, die dhāraṇi soll man entsprechend dem Maß und der Norm machen (?) und rezitieren." (Zieme 1996: 115).

BT VII 87-89: oom včir-a țutda sarva darm-a včir-a țutdo xang sarït qïlu üč qata sözläp adițdit qolunүu ol (Kara-Zieme 1976: 34). "om vajra [șuddah sarva] dharmah vajra suddho ham rezitierend. [drei]mal sprechen und um Segen [flehen]” (Kara-Zieme 1976: 34).

Dışastvustık 667-671: kim kayu tınl(1)glar bo dışastvustık atl(1)g sudur erdinig agız- da tutsar sarıt kılsar boşgunsar okısar nomlasar könüulte tutsar azu y(e)me etözde kö[(rkit)]ser ol kişi bir otuz katın ajunlarta togumın ödeçi çatısmarı bolur (Kaljanaova 2005: 113-114). "Herhangi bir canlı varlık Dışastuustık adlı bu sutra incisini ezberlese, öğrense, okusa, öğretse, akılda tutsa veya davranışlarıyla gösterse, o insan daha önceki 21 dünyadaki doğumunu hatırlayanlardan (jātismara) olur." (Kaljanova 2005: 130).

Dışastvustık 716-718: $s(a)$ rıt kılıp okı[(sar)]lar\{r\} ortusınta barmışda y(e)me köñülkermiş k(e)rgek... (Kaljanova 2005:119). "Bu Dışastvustık (adlı) sutra incisini bütünüyle öğrenip ezbere okusalar (bile)...” (Kaljanova 2005: 131).

UV o85-093: okıgu-ka sarıt kılg்u-ka : sakıngu-ka: bışrunġu-ka: ögü-kä: tapıngu-ka: tutg்u-ka:

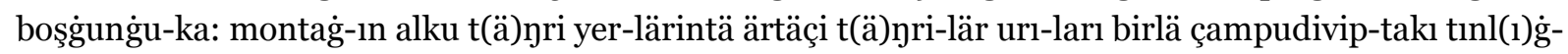
lar-nıy asıg்-lık-ı mänilik-i üçün bo darni birlä: mudur-nı tutuzur m(ä)n (İsi 2019: 156), (U II 1911: 3334). "Okumak, ezberlemek, düşünmek, öğrenmek, idrak etmek, ibadet etmek, bu öğretileri tutmak ve 
bunun gibi tüm Tanrı ülkelerinde yer alan Devaputralar ile birlikte Jambudvīpadaki canlıların mutluluğu ve selameti için bu dhāraṇi ile mudrāyı tutmanı emrediyorum." (İsi 2019: 190).

UV 154-158: tutdaçı: okıdaçı: sarıt kıltaçı tapındaçı: boşgiundaçı: äşidtäçi bar ärsär: ol oron-takı alku tınl(1)g்-lar ymä artokrak arı̀g süzök bolmak-ı bolur (İsi 2019: 164), (U II 1911: 38). “Tanrılar Hükümdarı Indra (hangi yerde olursa olsun) bu dhāranīyi yazmak, okumak, ezberlemek, ibadet etmek ve öğrenmek için duyulursa, o yerdeki tüm canlılar saf ve temiz olacaklar.” (İsi 2019: 191).

Tantrik Budizmin mantra ve dhāraṇ̄ terimlerinin uygulanma yöntemini bildiren sarıt sözcüğü, Budizm içerisinde bu büyü formüllerinin Budist inanırlarca akılda tutulmasını, okunmasını ve ezberlenmesini ifade etmektedir. Budizm içerisinde kendini gösteren yenilenme anlayışının ürünü olan büyü formülleri, Tibet'teki yerli halkın batıl inançlarına dayanmaktadır. Kendisini 7. yüzyılda gösteren bu Tantrik akım, Budizmin hâkim olduğu coğrafyalar içerisinde zamanla Budizmin var olan kuru ve sıkıcı üslubuna tepki olarak doğan bir harekettir. Budizm içerisinde Mahayāna mezhebine bağlı gelişen Vajrayāna ekolünün ürünü olan Tantrik Budizm, Uygurların Moğol hâkimiyeti altında tercih ettikleri dinî bir sistem olmuştur. Uygurların Moğol hâkimiyeti altında oluşturdukları Tantrik akımın ürünü olan eserler içerisinde yer alan mantra ve dhäraṇiler, vaat ettiği uzun yaşam, yeniden doğum gibi sözlerle Uygur Budizmine yeni bir hava katmıştır.

Eski Uygurca dönemine ait metinlere bakıldığında, sarıt sözcüğünün UV, Dışastvustık ve BT VII'de yer alan Tantrik eserlerde geçtiği görülmektedir. Tantrik Türk Budizmine ait dinî bir terim olarak sözcüğün AY I içerisinde yer alması, Uygur döneminde etkisini gösteren erken dönemli Tantrik etkilerden kaynaklanmaktadır. Bu doğrultuda, Eski Uygurcaya ait dört metin yoluyla tanıklanan sarıt ifadesi, Tantrik Türk Budizminin temel sözcüklerden biridir. İfadenin Uygur metinlerindeki yazımı noktasında

dikkat çekici husus, imla noktasında sarıt sözcüğünün Dışastvustık adlı eserin 669. satırında

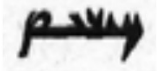

ilk hece ünlüsünün gösterilip 716. satırda ise sözcüğün muhtemelen yabancı bir dilden alınıp Türk fonetiğine uydurulması noktasında geçişler yaşadığını göstermektedir.

\section{Köken bilgisel olarak sartt (kl-) ifadesi}

İlk kez Eski Uygurca dönemine ait metinlerde tanıklanan sarıt kıl- ifadesi, sarıt ismi ile ve kll-yardımcı eyleminden meydana gelmiş birleşik bir eylemdir. Deyim görevinde genellikle Budist gelenek içerisinde dhāraṇ̄ ve sūtra'ların akılda tutulmasını anlatan bu söz, "tekrarlamak" anlamı yanında "ezberden okumak" (Şen 2017: 166) ifadesini de karşlamaktadır. Bu deyim, ayrıca "tekrarlamak, dilinden düşürmemek" (Şen 2017: 67) anlamındaki agızda tut- agızta tut- deyimi ile eş değerdir. Bu deyimi oluşturan sarıt sözcüğü, üzerinde köken bilgisel değerlendirmelerin yeterince yapıl(a)madığı ifadelerden biridir. Bu sözcük, Türk dilinin etimolojik sözlükleri arasında yer alan EDPT (Clauson 1972) ve VEWT (Räsänän 1969) adlı eserlerde yer almazken DTS'de bu kelime, deyim görevindeki sarït qül"ezberlemek" (Nadalyayev 1969: 489) anlamıyla gösterilip ifadenin geçtiği AY I ve Dışastvustık yayınlarına yönlendirilmektedir. Eski Uygurcanın dönem sözlüklerinden ve gramerlerinden EUTS (Caferoğlu 2011) ve ETG'de (Gabain 2007) ifadeye yer verilmezken 2014 yllında İsmail Doğan ve Zerrin Usta tarafından hazırlanan Eski Uygur Türkçesi Söz Varlı̆̆ (2014: 275) adlı eserde kelimenin AY I ve Dışastuustık yayınlarındaki tanıklarına yer verilerek herhangi bir anlamsal ve köken bilgisel değerlendirmelere girişilmemiştir. U II'de Müller, ifadeyi "zum *Recitieren” (1911: 33) olarak vermektedir. BT VII'de Kara ve Zieme, sarït qül- ifadesini “rezitieren” (1976: 95) olarak verip okuyucuyu 
A 87 numaralı dipnotta AY, U II ve Dışastuustık yayınlarına yönlendirmektedir (1976: 34). BT XVIII'de Zieme, sözcüğ̈̈ “Rezitation: ezber" olarak verip kelime hakkında herhangi bir değerlendirmeye girişmez (Zieme 1996: 223). Kaljanova, Dışastuustık yayınında sartt kıl- ifadesini oluşturan isim unsuru görevindeki sarıt sözcüğü hakkındaki değerlendirmeleri tanıklarla göstermektedir. Kaljanova, sözcükle ilgili tanıkları gösterdikten sonra kelime hakkında Tezcan'ın bahsettiği değerlendirmelere yönelse de kelimenin kökeni hakkında herhangi bir görüş bildirmemektedir (Kaljanova 2005: 160). Tezcan, BT VII A 87'de yer alan sart kal-ifadesinin "makamla ezbere okumak" anlamında olduğunu belirtip bu deyimi oluşturan sarıt sözcüğünün Türkçe ise, Türkmence sarna- ve sarnaş- "bir şeyler söylemek, mırıldanmak" ifadeleri ile karşılaştırılabileceğini belirtmektedir. Tezcan’ın köken bilgisel yönden sözcüğün Türkçe ya da yabancı kökenli olduğu noktasında kesin bir görüşü söz konusu olmasa da, yukarıda zikredilen araştırmacılardan farklı olarak kelimeye yönelik deneme girişiminde bulunması, dikkat çekicidir (Tezcan 1979: 305). Tezcan'ın belirttiği, Türkmence sarna- ya da sarnaş- sözcüklerine bakıldığında, eylemlerin "mırıldanmak" (Tekin vd. 1995: 563) anlamında olduğu görülmektedir. sarnaeylemi içerisinde yer alan -rn ünsüz çifti, Türkçenin ünsüz çifti sistemine aykırı bir birleşimdir. Bu ünsüz çifti, bize - $r$ ve $-n$ sesleri arasında dar bir ünlünün bulunduğunu ve zamanla bu dar ünlünün düştüğünü göstermektedir. Bu durumdan hareketle, Tezcan'ın bahsettiği ilgili eylemlerin sarma- ya da sarma-şşeklinde olduğu görülmektedir. Türkçede bazı istisna kelimeler dışında, iki ya da üç heceli kelimelerin türemiş bir sözcük olduğu göz önüne alındığında, eylemin *sarın+a- şeklinde morfolojik açllıma sahip olduğu görülmektedir. EDAL'da (Starostin 2005: 1218) -sarV madde başıyla "şarkı, festival, eğlence" anlamındaki sari sözcüğü gösterilmektedir. Proto Tunguzcada *sari-n ve Mançucada sarin şeklinde görülen bu ifade, Proto Türkçede *sarin şeklinde "şarkı" anlamına gelmektedir. Proto Türkçe dışında bu ifade, Türkmence, Kazakça, Kumukça ve Oyratça gibi dillerde sarin olarak görülmektedir. Starostin ve ekip arkadaşları tarafından varsayımsal olarak tasarlanan sari sözcügü, Eski Uygurcaya ait metinlerde karşımıza çıkan sarıt ifadesi ile ilişki olabilir. Temel anlamı ses olan "mırıldanmak, dilinden düşürmemek" anlamındaki sarıt ifadesi Budist Uygur geleneği içerisinde öneme sahip dhāraṇ̄ türüne ait metinlerin tekrarını ifade etmesi ile bilinen bir sözcüktür. Bu doğrultuda, sarıt sözcüğünün *Proto Türkçe $s a R V$ ve isimden isim yapan $+t$ ekinden türediği düşünülse de, $+t$ ekinin eski bir çokluk eki olarak oght, yılpagut, kanat, tigit (Tekin 2016: 97) gibi kalıplaşmış ifadeler türetmesi, sarıt sözcügünü oluşturan kök ve ekin birbiriyle ses ve işlev bakımından uyuşmadığını göstermektedir. Yıldız, çalışmasında sarıt kıl- ifadesi ile ilgili "Kayıt-Saklama fiillerinin \{+DA\} TUT-(MAK) yapısında agızda tut-(mak) ve köyülte tut-(mak) şeklinde birleşik fiiller olması ile agız ve köyül kelimelerinin BELLEK kavramı için kullanılması dikkate değerdir. Ayrıca, 'akılda tutmak, hıfzetmek, ezberlemek, bellemek' anlamında basit veya türemiş bir fiilin tarafımızdan tespit edilememiş olmasıyla beraber; kayıt-saklama filleri kategorisine girmeyen, ancak derin yapısında EZBER kavramını bulundurarak 'ezberden okumak/söylemek' anlamına gelen agzan-(mak), okı-(mak), sarıt kıl-(mak) ve takşur-(mak) fiilleri de dikkatlerden kaçmamalıdır." (2019: 30) açıklaması, sarıt kıl- ifadesiyle ilişkili "Bellek Fiilleri" kavramına işaret etmektedir. Uzunkaya ise sarıt kıl- fiili ilişkili değerlendirmelerini "Her nerede bu dhāraṇi gösterilecek olursa, eğer bilhassa yazılırsa (Uyg. bitițdäçi; Çin. 書寫 shuxie), okunursa ve ezberlenirse (Uyg. okıdaçı, sarit kıltaçı; Çin. 受持讀誦 shouchi dusong) vb. o yerde bütün canlılar ziyadesiyle arınır." (2019: 112) ifadesi ile ortaya koyarak ilgili yapının sarit kıl- olarak okunacağını göstermiştir.

Eski Uygurca sarıt kıl-ifadesinde tanıkladığımız sarıt sözcüğü ile ilişkili diğer bir görüş, sözcüğün hem toplumsal yaşamın sürekliliğini gösteren ticari faaliyetler hem de manevi yaşamın devamını sağlayan dinî etkiler kaynaklı dil ilişkileri sonucu, Türkçeye ödünçlenmesine dayanmaktadır. Bilindiği gibi, Türk dillerinin İranî dillerle teması ve bu temas sonucu yaşanan dilsel ve toplumsal değişmeler her ne kadar yazılı olarak Köktürkçe döneminde görülse de, İranî etkilerin bu dönemden daha önceye gittiği bilinen 
bir durumdur. Türk-İran etkileşimi içerisinde gerçekleşen kültürel aktarımlar çift yönlü bir gelişme izleyerek diller arasında etkilenmelerin önünü açmıştır. Orhon Türkçesi metinlerinden itibaren doğrudan veya dolaylı olarak İran dillerinden özellikle dinî hayat, idari ve askerî örgütlenme ile ilgili çok sayıda sözcüğün kopyalandığı metinler yoluyla görülmektedir (Eker 2009: 234-236). Özellikle Budizm doğrultusunda toplumsal bir yaşam inşa eden Uygurlar, toplumsal yapılarını düzenleyen gelişmeler konusunda İranî kavimlerden özellikle Soğdlardan ilgili kültüre adapte olma adına yardımlar almıştır. Budizme ait öğretileri, doğrudan kaynak dil konumundaki Sanskritçe ve Çinceden değil de, Soğdca ve Toharcadan elde eden Uygurlar, bu dillere ait sözcükleri, aynı şekilde Soğdca ve Toharca üzerinden Türk diline aktarmıştır. Tibet Budizmine ait metinlerin anahtar kelimelerinden olan dhāraṇī "büyü” okuma ya da ezberleme ritüelinin tekrarını ve akılda tutulmasını sağlayan sarıt ifadesi, ses ve anlam bakımından Soğdca sr'wty'= srūtyā "şarkı” (Gharib 1995: 360) kelimesi ile ilişkilidir. Sözcük, Pehlevicede srōd "şarkı" (Mackenzie 1986: 76) şeklinde olup Modern Farsçada da soru:d "marş, şarkı" anlamında kullanılmaktadır. Ses ve anlam açısından Eski Uygurca sarıt ifadesi ile uygunluk gösteren Soğdca srūtya ve Pehlevice srōd kelimeleri, Uygurlar ve İranî kavimler arasındaki kültürel ve ticari ilişkilerin ürünüdür. Soğdca srūtya ve Pehlevice srōd biçimlerinden dilimize geçen bu ifadenin ödünç bir kelime olduğuna dair deliller arasında, sarıt (kıl-) ifadesinin hem dinî bir terim olması hem de Eski Uygurca metinlerde özellikle Dışastvustık temelinde ilk hece ünlüsünün yazımında ikilik görülmesi yer almaktadır. Dışastvustık metninde sözcüğün ilk hece ünlüsünün gösterimi noktasında yaşanan ikilik sözcüğün Türk fonetiğine uyarlanması açısından geçişler yaşadığını göstermektedir. sarıt sözcüğü özelinde gördüğümüz bu ikiliği, darni sözcüğü özelinde Eski Uygurcanın ilk ve son dönem metinlerinde görürüz. İlk dönem Uygur metinlerinde ilk hecede ünlüsü gösterilmeden $d(a) r n i$ şeklinde yazılan Sanskritçe dhāraṇi ifadesi, sonraki metinlerde özellikle Tantrik Türk Budizmine ait Uṣnịșa Vijayā Dhāraṇi Sūtra ve Sitātapatrādhāraṇi gibi eserlerde, ilk hecesi ünlülü darni şeklinde yazılmaktadır. Tantrik Türk Budizmi metinleri dışında AY I'de tanıkladığımız sarıt yazımı, erken dönem Tantrik etkilerden kaynaklı istisna özelliği taşımaktadır.

Uygur Budizminin beslendiği kaynaklardan olan Soğd ve Tohar Budizmi içerisinde "şarkı" anlamlı srūtya sözcüğünün "ezber" kavramına işaret eden anlama geçişi, özellikle büyü formüllerinin akılda kalması adına dhāraṇilerin belli tekrarlar ve ezgi ile söylenmesi ile ilişkilidir. Budistlerce kutsal sayılan bu büyü formüllerini bir şarkı gibi dilden düşürmemeleri, zamanla bu kavramın zihinde tutulmasını sağlamıştır. Bu durumu sarıt ifadesinin Dışastvustık 667-671. satırlarda eş anlamlı agızda tut- ifadesi ile birlikte kullanımı ile görürüz. Bu da sözcüğe dair anlam geçişinin zihinsel olarak "ezber" kavramına ulaştığı sonucunu göstermektedir.

\section{Sonuç}

Türk dilinin Tantrik Türk Budizmi döneminin dinî terminolojisi içerisinde mantra ve dhāraṇ̄ denilen büyü formüllerinin öğrenilmesini, akılda tutulmasını ve ezberlenmesini karşılayan sarıt sözcüğü, Eski Uygurca dönemine ait dört metinde tespit edilmiştir. Tespit edilen dört metin içerisinde sart sözcüğünün Budizmin öğreti türü olan mantra, dhāraṇ̄ ve sūtra terimlerini anlattığı görülmektedir. Kelime ile ilgili değerlendirmeler ve tanıklar göz önüne alındığında, sözcük İranî bir dilden Eski Uygurcaya aktarılmıştır. Eski Uygurcaya aktarılan bu sözcüğün kaynağının Pehlevice ya da Soğdca gibi İranî dillerden olduğu, Proto Türkçe *sari+t birleşimindeki şekil ve anlam uyumsuzluğundan dolayı daha güçlüdür. Türk dilinin Orhon Türkçesi dönemine denk gelen olası Pehlevice ilişkiler bir yana bırakılırsa, Eski Uygurca döneminde Uygurların Soğdlarla giriştikleri ticari temas yanında, Soğdların Budizm ve Budizme ait kavramları Uygurlara öğrettiği gerçeği düşünüldüğünde, dil ilişkileri bağlamında kelimenin Soğdca srūtya biçiminden ödünçlenmesi mümkündür. 


\section{Kaynakça}

Doğan, İ. ve Usta, Z. (2014). Eski Uygur Türkçesi söz varhğı. Ankara: Altınpost.

Eker, S. (2009). Divanü Lugâti't-Türk ve İran dillerinden kopyalar üzerine I. International Journal of Central Asian Studies, Volume 13, 233-283.

Gharib, B. (1995). Sogdian dictionary Sogdian-Persian-English. Tahran: Ferhangan.

İsi, H. (2019). Eski Türkçe Tantrik Bir Metin: Ușn̄ișa Vijayā Dhāraṇi Sūtra. Yayımlanmamış Doktora Tezi. Ankara: Hacettepe Üniversitesi Sosyal Bilimler Enstitüsü. [UV]

Kaljanova, E. (2005). Uygurca Dışastuustık (giriş, metin, çeviri, dizin ve tıpkıbasım). Yayımlanmamış Doktora Tezi. İstanbul: Marmara Üniversitesi Türkiyat Araştırmaları Enstitüsü.

Kara, Györg ve Zieme, P. (1976). Fragmente tantrischer werke in uigurischer übersetzung. Berliner Turfantexte VII. Berlin: Akademie Verlag.[BT VII]

Kaya, C. (1994). Uygurca Altun Yaruk: giriş, metin ve dizin. Ankara: Türk Dil Kurumu.

MacKenzie, D.N. (1986). A Concise Pahlavi Dictionary. London: Oxford Unıversity Press.

Müller, F. W. K. (1911). Uigurica II. Berlin: Abhandlungen der Königlich PreußischenAkademie der Wissenschaften. [U II]

Nadalyayev, B.M. ve diğer.(1969). Drevne Tyurskiy slovar'. Leningrad: Nauka.[DTS]

Starostin, S.A. ve diğer. (2005). An etymological dictionary of Altaic language. Leiden-Boston: Brill. [EDAL]

Şen, S. (2017). Eski Türkçenin Deyim Varhğı. Ankara: Türk Dil Kurumu.

Tekin, T. ve diğer.(1995). Türkmence-Türkçe Sözlük. Ankara: Türk Dilleri Araştırmaları Dizisi 18.

Tekin, T. (2016). Orhon Türkçesi grameri. Ankara: Türk Dil Kurumu.

Tezcan, S. (1978-1979). TANITMALAR: Georg Kara-Peter Zieme: Fragmente tantrischer Werke in uigurischer Übersetzung. Türk Dili Araştırmaları Yillı̆̆ı - Belleten, Sayı 1978-1979, 301-306.

Uzunkaya, U. (2019). Eski Uygurca Ușnīṣavijayā-nāma-dhāraṇi üzerine. RumeliDE Dil ve Edebiyat Araştırmaları Dergisi, (16), 106-125.

Yıldız, H. (2019). Eski Uygurcada Bellek Fiilleri. Türkbilig, 2019/37, 21-34.

Zieme, Peter (1996). Altun Yaruq sudur. vorworte und das erste buch. Berliner Turfantexte XVIII. Brepols: Belgium. [AY I] 